\title{
SUSTENTABILIDADE, O DESAFIO DAS POLÍTICAS SOCIAIS NO SÉCULO 21
}

Ruth Cardoso

\begin{abstract}
Resumo: Estamos em um momento em que é grande a expectativa de que as políticas sociais sejam mais eficazes no combate à pobreza. Reconhecida a ineficiência do modelo assistencialista, durante a década de 90, muitos projetos inovadores foram desenvolvidos por governos e por organizações do Terceiro Setor, abrindo caminho para intervenções eficientes voltadas para a mobilização das comunidades e o desenvolvimento de capital social.

Palavras-chave: políticas sociais focalizadas; participação; capital social.
\end{abstract}

Abstract: At the moment, we are facing great expectations of having more effective social politics to combat poverty. Once the inefficiency of the assistance model of the 90's was recognized, governments and third sector organizations developed many innovative projects. They opened new ways for effective interventions aimed to mobilization of the communities and the development of the social capital.

Key words: focused social politics; participation; social capital.

Para alcançar êxito, os programas de combate à pobreza precisam abandonar o olhar que vê carências e buscar localizar as potencialidades.

A tualmente, quase todas as políticas e propostas que partem das empresas e do Terceiro Setor têm como objetivo o combate à pobreza e à exclusão social. $\mathrm{O}$ que antes era uma tarefa dos governos passou a ser visto como uma obrigação de todos. A consciência da necessidade de eliminar do mundo a mancha da fome, da falta de acesso à educação, à saúde e à garantia dos direitos humanos básicos é, hoje, generalizada. Com certeza, no Brasil, existe disposição para não mais se aceitar a enorme desigualdade que, tradicionalmente, vem marcando nossa sociedade. A mobilização de todos os setores é grande e os veículos de comunicação informam, constantemente, tanto sobre a persistência da pobreza quanto sobre a necessidade de combatê-la. Entretanto, apesar da presença constante do tema na mídia impressa e falada, estes veículos não têm apresentado análises e avaliações (que existem) sobre o fracasso de soluções apresentadas como milagrosas, ou sobre a inoperância de programas com longa trajetória.

Não é só no Brasil que o tema tornou-se central. Existe, entre nossos vizinhos latino-americanos, africanos e também nos países desenvolvidos, a mesma impaciência com a marca de um mundo globalizado, onde a excelente qualidade de vida de alguns convive com situações subumanas. Nunca tivemos um período em que houvesse tanta clareza e também tanta indignação com a extrema desigualdade.

Este é certamente um momento positivo para um debate sobre novos caminhos para uma sociedade melhor.

Por um lado, muitos fatos novos exigiram a revisão das tradicionais políticas de assistência às populações em situação de risco. A primeira mudança significativa veio com a crise fiscal dos Estados, que obrigou a uma revisão das despesas com políticas sociais. Este fato, negativo por trazer limitações aos gastos, também proporcionou condições para uma re-análise das concepções de assistência social e do alcance e efetividade dos programas governamentais tradicionais.

Por outro lado, muitas experiências novas foram implementadas com sucesso, especialmente durante os anos 90. E, ao mesmo tempo em que estas propostas inovadoras se firmavam, também se expandia um Terceiro Setor que ganhou força e colaborou para que experiências bemsucedidas fossem implantadas em muitas regiões do mundo. Este campo de experimentação progrediu muito, mas 
a difusão das idéias novas ainda é precária devido tanto à fragmentação das experiências quanto à pouca legitimidade acadêmica atribuída a essas discussões.

Entretanto, a impaciência com a persistência da pobreza, apesar das políticas sociais cujo objetivo seria combatêla, legitimou alguns temas dominantes no debate da mídia durante os últimos anos.

O primeiro deles foi a necessidade de focalização dos programas para atingir seu público-alvo - os mais pobres - e o segundo foi a crítica ao assistencialismo.

Esses dois aspectos dos programas sociais foram considerados responsáveis pelo contínuo fracasso do combate à pobreza.

Entretanto, como conseqüência da ampliação do debate, houve também a politização destes temas, que se tornaram mais ocasiões para denúncia do que oportunidade para o diálogo construtivo. Para alguns, a persistência da pobreza é a prova da ineficiência das políticas governamentais; para outros, é preciso que se destinem mais verbas à área social para que os programas sejam ampliados. Neste clima, as críticas foram muitas vezes pouco concretas.

Certamente o assistencialismo precisava ser arduamente criticado e o foi, gerando quase a eliminação da palavra. Na verdade, porém, não houve interesse em sumarizar os conhecimentos existentes sobre a falência das ações assistencialistas e nem delimitar em que situações grupos fragilizados necessitam de assistência. Assistência não se confunde com assistencialismo, mas, dado o alarme contra esta prática, as duas palavras foram desqualificadas.

Entretanto, ainda hoje com freqüência nos deparamos com programas sociais, governamentais ou filantrópicos que apresentam uma retórica antiassistencialista, mas cuja prática repete os velhos métodos.

O que já se sabe com certeza é que estas práticas não eliminam a pobreza e não criam envolvimento dos pobres para combatê-la, mas faltam avaliações objetivas que ajudem a definir os aspectos negativos e, se houver, os positivos das ações tradicionais.

Assistencialismo é um estilo, é um modo de fazer, que tem como conseqüência criar uma relação de submissão e não oferecer os instrumentos para superação das carências que estão sendo minoradas. Quando associadas ao clientelismo, as formas de assistência se transformam em instrumentos de poder. É bom lembrar que, se os governos podem ser os espaços privilegiados para o clientelismo, não são os únicos, pois é possível encontrar estes mesmos usos em entidades privadas.
Acredita-se que a relação clientelística tem seus dias contados em uma sociedade de comunicação de massa e, atualmente, já não possui a eficiência que teve no passado, porque os controles sobre a clientela foram se tornando mais frouxos.

$\mathrm{O}$ assistencialismo continua perdendo força nas sociedades contemporâneas, porque já se sabe que reproduz a pobreza em vez de combatê-la. Entretanto, apesar disso, continua a ser praticado porque é fruto de uma visão filantrópica ainda muito generalizada.

Nesta visão, os pobres são aqueles que têm renda insuficiente e pouco acesso à educação, à saúde e ao emprego. As camadas mais pobres, por serem caracterizadas só a partir de suas necessidades, têm sido designadas como carentes ou excluídas - expressões que traduzem distância entre os que fazem parte da sociedade (e falam) e aqueles que estão fora e para quem só existem obstáculos a serem reconhecidos e removidos. Este modo de olhar propõe sempre doações que atendam às necessidades que o observador de fora diagnostica. Ao terem supridas suas carências, espera-se que os beneficiários ganhem força para enfrentar, sozinhos, a falta de oportunidades com que convivem no dia-a-dia. Esta é a velha concepção de filantropia que ainda hoje está bem implantada e que justifica a volta de práticas assistencialistas e clientelísticas, mesmo quando não se usam essas expressões.

O debate sobre a segunda questão - a focalização dos programas - vem ganhando força pela pressa que nossa sociedade tem de eliminar as desigualdades e também pela legitimidade que as ações afirmativas ganharam desde os anos 70. A luta das mulheres, dos negros, dos deficientes, da terceira idade, dos homossexuais, etc. criou reconhecimento para ações específicas e dirigidas a setores discriminados.

Entretanto, é preciso ver as diferenças entre os programas de ações afirmativas decorrentes de uma demanda política dos setores mobilizados e as ações de combate à pobreza, sejam estas governamentais ou não.

$\mathrm{Na}$ maioria dos programas que buscam a focalização, os pobres constituem um segmento definido por critérios estatísticos, o que não define um ator social, mas sim um grupo heterogêneo que tem em comum um mesmo nível de renda. Por esta razão, as ações de combate à pobreza que partirem deste tipo de focalização não contarão com interlocutores participantes, capazes de mobilizar identidades comunitárias. Como conseqüência, os projetos de desenvolvimento social dirigidos aos mais pobres podem e devem se inspirar no modelo das ações afirmativas, mas 
precisam estar cientes de que a participação não decorre da focalização.

Localizados os pobres e feitas as doações, não aparecerá, como conseqüência, uma resposta espontânea destes indivíduos em apoio aos incentivos oferecidos. Pelo contrário, para ser incluído no mercado, quer como consumidor quer como trabalhador, é preciso ir além da superação da fome, da doença, etc. É necessário desenvolver auto-estima, capacidade de comunicação e, ainda, confiança em seus saberes e em sua capacidade de aprender. Estas qualidades existentes em comunidades de pouca renda são mais fáceis de serem generalizadas quando há envolvimento coletivo e quando o grupo que está recebendo atenção se transforma em protagonista de sua mudança. Quando isso acontece, são capazes de definir as ações afirmativas que podem ser eficientes em cada contexto.

Sem dúvida, uma clara definição do público-alvo (focalização) é essencial para o êxito do combate à pobreza, mas precisa-se também de uma metodologia nova que desenvolva as capacidades latentes existentes nestes grupos selecionados, abandonando o olhar que vê carências e buscando localizar as potencialidades. Existe uma rica literatura, nacional e internacional, que discute esta nova noção de desenvolvimento social, que parte da promoção do capital social. ${ }^{1}$ Também já há consenso sobre a eficácia desta abordagem.

Portanto, é importante integrar ao debate sobre a focalização esta outra discussão a respeito das inovações metodológicas que necessitamos para tornar mais eficaz o combate à pobreza.

Em estudo recente, Ricardo Barros e Mirela de Carvalho (2003) reafirmam o que já vinham dizendo com muita ênfase em outros trabalhos: que a grande falha da política social é a falta de focalização e que só teremos melhores indicadores se houver canalização de recursos para os mais pobres. Entretanto, os autores ampliam sua visão indicando que "três desafios merecem destaque: em primeiro lugar, ressaltamos a necessidade de uma política social flexível, uma vez que, apesar da pobreza ser um problema global, sua solução é tipicamente local. Em segundo lugar chamamos atenção para a efetividade e, portanto, para o fato de que o sucesso de uma política social depende enormemente do grau de cooperação e engajamento da população pobre beneficiada. Desta forma, um importante desafio consiste em identificar formas de estimular esta participação. Por fim ratificamos que qualquer mudança na política social brasileira será incapaz de elevar sua efe- tividade no combate à pobreza enquanto não se adotar uma clara opção pelos mais pobres".

Infelizmente, neste artigo, os autores não levam mais longe a discussão das características necessárias às propostas de combate à pobreza para que sejam flexíveis e participativas.

Localizados os desafios, são necessários caminhos para enfrentá-los, e o primeiro passo pode ser uma sumarização daquilo que já se sabe sobre sucessos e fracassos no combate à pobreza.

\section{OPÇÃO PELOS MAIS POBRES}

Para evitar a ilusão de que, através da concentração de programas, pode-se mudar a realidade, é preciso lembrar alguns exemplos relativamente recentes, de direcionamento radical das políticas sociais para os mais pobres.

Foi o que ocorreu no Chile, de Pinochet, onde foram ineficazes os esforços para dirigir rigorosamente os gastos públicos para os indigentes. Apoiados nas concepções liberais que fundamentavam as políticas econômicas do regime militar chileno, os programas sociais tinham como meta assistir aos pobres através de subsídios, e foram planejados para evitar fuga de recursos para outros grupos que não seu público-alvo. Esta fuga de recursos foi corretamente diagnosticada como responsável pelos fracos resultados dos governos anteriores no combate à pobreza.

Para trabalhar com maior precisão, foram criados instrumentos adequados para classificar as famílias (fichas e visitas). O cadastramento foi descentralizado para garantir maior confiabilidade e seguiram estas receitas com rigor. Tinham também grande poder sobre a burocracia para a execução dos programas considerados de emergência e, para tanto, criaram agências especiais, distribuídas por todo o país, mas com controle centralizado.

A seleção dos beneficiados pelos programas de pensões familiares, educação pré-escolar subsidiada, distribuição de alimentos, atendimento gratuito à saúde e programas especiais de emprego, grosso modo, atenderam aos critérios da focalização desejada pelos planejadores. Entretanto, este grupo de beneficiários, considerado indigente, foi discriminado pela sociedade, e suas oportunidades de inclusão diminuíram.

Como diz Graham (1991:19), "The fact that the workers were often stigmatized by working in the programs created even greater barriers to entrance to the formal sector. Underemployment rates and the size of the informal sector remained the same or grew in the decade the programs were in place." 
Os livros de Vergara (1990) e de Graham (1991) foram escritos no fim do período do governo Pinochet e apresentam análises bastante objetivas do que foram essas políticas sociais e suas limitações: "Unfortunately, the military's authoritarian nature and approach undermined the potential of its policies. The government's narrow and vertical approach to poverty alleviation - providing subsidies rather than investment in human capital - was palliative and encouraged dependence. A segment of the population was publicly stigmatized and became increasingly dependent on the state for subsidies to meet its basic needs" (Graham,1991:11-12).

Graham apresenta um panorama das mudanças propostas pelo governo do presidente Aylwin, eleito em 1990, que procuram responder as limitações da extrema focalização anterior e desenvolver políticas mais participativas. Foi criado um Fundo de Solidariedade e Investimento Social - Fosis, cuja finalidade era desenhar programas que estimulassem as participações comunitária e da sociedade civil mobilizada. Essa mudança definiu um claro contraste com o modelo anterior e respondeu à demanda da sociedade civil chilena, cuja mobilização fora fundamental para a vitória da oposição.

Quais as lições que esta experiência ensina? Que a focalização não é uma panacéia, mas sim um recurso fundamental e indispensável quando combinado com uma nova visão do que seja desenvolvimento social. Por sua vez, esta nova visão impõe projetos flexíveis, capazes de promover as lideranças locais e a participação comunitária, criando envolvimento com as demandas e com a busca de soluções sustentáveis.

Já se dispõe, portanto, de lições aprendidas, mas não é e não foi fácil mudar orientações tradicionais para renovar as políticas sociais. Vários países da América Latina, no início dos anos 90, conscientes da perversa perpetuação da pobreza, enfrentaram o desafio da renovação de seus programas sociais, buscando atingir os segmentos mais pobres.

Em alguns países, durante este período, tiveram início projetos desenhados para deixar de lado o clientelismo e o partidarismo, buscando-se a eficácia. Os governos, ainda vistos como responsáveis pelas políticas públicas, ensaiaram novos programas que, com frequiência, foram atropelados pelas descontinuidades devidas às mudanças de dirigentes, restos de clientelismo e resistência da burocracia.

O México foi um dos primeiros a encaminhar essas mudanças, substituindo o programa Pronasol pelo Progresa, em que a focalização foi definida com cuidado e a assis- tência às famílias selecionadas foi planejada por um período mais longo, necessário para sua integração. O cuidado com que foi planejado este último programa garantiu um avanço na definição dos beneficiários e um razoável desempenho. Felizmente, o novo governo eleito não abandonou o trabalho em curso e deu mais um passo no caminho da coordenação das ações, enfatizando ainda mais a necessidade de promover o capital social das comunidades. Para tanto, foi introduzida uma estratégia denominada "Contigo", que pretendia ser "an overall effort to bring coherence to the multiplicity of existing social programs under a Social Cabinet to which participate seven secretariats and five institutes." (Janvry; Sadoulet, 2003:1). Segundo estes autores, o aspecto mais interessante desta estratégia para o desenvolvimento social está no fato de ter sido estruturada a partir de um rigoroso quadro conceitual no qual tinham papel central o empoderamento (empowerment) das comunidades e o fortalecimento da cidadania. Só deste modo os pobres podem atuar como agentes da sua própria mudança. Atualmente está enraizada a convicção de que a mudança social só ocorre a partir do contexto local, o que obriga a manter flexível o monitoramento dos programas para que novos parceiros possam ser incorporados e objetivos revistos com o acordo dos participantes.

Como já indicado anteriormente, as novas concepções sobre políticas de combate à pobreza não são fáceis de serem implementadas. Janvry e Sadoulet (2003:1) procuraram avaliar avanços e analisar dificuldades partindo da constatação de que "while some of these programs have been subjected to extensive external evaluation, the mecanisms to internalize lessons learned into improved program design and management remain very weak". Nas conclusões, apresentam sugestões coerentes com os princípios que norteiam as intervenções, mas discutem caminhos mais diretos para alcançar os resultados esperados. Por exemplo: sugerem em sua terceira conclusão que "The efficiency of cash transfer programs for education, health, and nutrition could be greatly increased by targeting and calibrating transfers on children at risk of acquiring each of these basic needs, as opposed to targeting on poverty." (Janvry; Sadoulet, 2003:30). Esta indicação mostra que este modelo de intervenção exige uma disposição contínua e sistemática para aprender com e durante o processo de mudança social. Para rever os critérios de distribuição de recursos, tal como foi sugerido, é preciso revisitar a definição do público-alvo original e estipular novo foco para a ação. Analisando este exemplo, fica claro que, por 
um lado, qualquer estratégia de combate à pobreza deve partir de critérios precisos para definição do segmento que pretende beneficiar (focalização). Por outro, se pretenderem privilegiar o desenvolvimento social local e o protagonismo destes atores, os programas devem garantir um processo de incorporação das lições que vão sendo apreendidas durante o desempenho dos vários atores.

A experiência mexicana exemplifica bem a preocupação que se expandiu na América Latina, durante os anos 90, com a renovação das políticas sociais. Na maioria dos países o debate sobre os novos rumos das políticas sociais teve início e, os organismos financiadores internacionais (Banco Interamericano de Desenvolvimento, Banco Mundial) também se engajaram na discussão sobre as parcerias com a sociedade civil e novas metodologias que promovem a participação.

Estas experiências, porém, mostram também as dificuldades para introduzir novos conceitos e novas práticas neste campo de ação. Entretanto, muitas iniciativas deixaram suas marcas e abriram caminhos durante a década de 90 (De Franco, 2001:91), e esta renovação só foi possível porque, nos anos 80 , caracterizados como a década perdida para o desenvolvimento econômico brasileiro, houve um período rico para a organização da sociedade civil (Cardoso, 1995), que trouxe como resultado novas abordagens no trato com problemas sociais crônicos.

As novas formas de participação e mobilização abriram as portas para as parcerias entre governos (locais, estaduais ou federais) e ONGs, empresas (grandes e pequenas), universidades e associações de vários tipos. Novos atores sociais se mobilizaram fora do Estado e muitas vezes contra ele, naqueles países onde a luta contra a ditadura desenvolveu uma nova concepção da responsabilidade do cidadão e da participação democrática.

As políticas sociais ainda eram vistas como uma atribuição do Estado, mas as parcerias com as empresas e as organizações civis, ao mesmo tempo que a democracia, começaram a criar raízes. O espaço público já não se confunde com o espaço governamental, e o desejo de resultados eficazes no combate aos problemas sociais crônicos provocou uma ampliação das parcerias com vistas à programação de intervenções eficazes.

O objetivo destas parcerias não é diminuir a responsabilidade dos governos na construção de uma sociedade mais igualitária, mas sim incorporar as inovações metodológicas e conceituais desenvolvidas no Terceiro Setor, por meio das experiências bem-sucedidas em vários campos. Governo e sociedade trabalhando juntos conseguem operações de menor custo e maior eficácia e, o que é ainda mais importante, uma maior participação das comunidades envolvidas.

Entretanto, como o nome indica, parceria significa uma relação entre iguais e liberdade para a tomada de decisões. Não pode haver hegemonia dos propósitos dos governos, porque os parceiros devem concordar quanto aos objetivos, aos métodos de atuação e à transparência durante a execução dos programas. Esta nova relação de trabalho exige que as partes envolvidas sejam abertas ao aprendizado, porque, se as agências de governo têm de respeitar procedimentos consagrados e atender legítimas demandas políticas, a sociedade civil, por sua vez, quer resultados rápidos e só confia em seus métodos. São lógicas diferentes que precisam encontrar um patamar comum para que se possa avançar na construção de uma sociedade mais igualitária.

\section{DILEMA ENTRE O UNIVERSAL E O ESPECÍFICO}

A insistência em privilegiar os mais pobres na distribuição dos programas sociais nos coloca diante de outro dilema: qual o critério para estabelecer a partilha dos recursos públicos entre os programas com público-alvo específico e aqueles que correspondem ao direito de todos os cidadãos e que costumam ser chamados de programas universais? Além das limitações orçamentárias que existem em todos os países com uma larga proporção de pobres, observou-se pelo exemplo chileno, que um excesso de focalização pode criar mais pobreza, pois, sem criar incentivos para a autonomia dos atendidos, os programas só podem funcionar com uma alocação crescente de recursos.

O dilema da partilha de recursos públicos parece sem solução, porque sem crescimento econômico contínuo (um desejo dificilmente realizável) não é possível ampliar, no prazo e na proporção necessários, o número de pobres beneficiados. Nosso país, que tem uma dívida social enorme e antiga, não pode continuar levando a sério propostas irrealistas sobre distribuição de recursos monetários para os pobres sem considerar que esses mesmos pobres precisam aumentar sua presença nas escolas, nos postos de saúde, nos transportes coletivos e ter acesso à moradia, à segurança pessoal, etc.

Cabe ao Estado garantir a infra-estrutura necessária para que este atendimento seja efetivo. Não se pode definir prioridades entre combater os focos de pobreza ou am- 
pliar e aperfeiçoar os serviços públicos básicos. O equilíbrio tem de ser encontrado distribuindo-se os recursos necessários para programas eficazes, que elevem a qualidade de vida dos pobres, sem prejuízo da ampliação do atendimento universal nas áreas de educação, saúde, segurança e direitos humanos.

Os setores discriminados necessitam de uma política afirmativa para conseguirem sua inclusão como consumidores dos serviços públicos. Portanto, as intervenções executadas por grupos da sociedade civil são indutoras de demanda e devem trabalhar em sintonia com as dificuldades e com as oportunidades que podem ser exploradas no espaço público. Um bom exemplo desta cooperação é o programa Alfabetização Solidária, que mobiliza recursos de empresas e universidades para trazer jovens e adultos para salas de aula, naqueles municípios onde as taxas de analfabetismo são extraordinariamente altas. Conseguindo criar o interesse pela aprendizagem, as próprias universidades e o núcleo articulador do programa procuram apoiar as prefeituras na implantação de cursos regulares para jovens e adultos. Nesta parceria, os atores que participam do Alfabetização Solidária conseguem realizar uma tarefa difícil para os governos, que é localizar e reunir os analfabetos e mostrar que têm capacidade de aprender. Entretanto, o trabalho não termina quando os alunos alcançaram um nível mínimo. Os professores procuram entusiasmá-los para continuar o aprendizado nas salas de aula do sistema público. As instituições de ensino superior e o núcleo coordenador do programa levam informações e apoio para que os governos locais possam disputar os recursos disponíveis para esta modalidade de ensino, colaborando para sua expansão.

A sociedade civil, ao planejar suas intervenções, deve ter em mente o lugar que ocupam seus projetos no conjunto das oportunidades oferecidas. Isto significa que, se existe uma ação na área de educação ou saúde, focalizada em um grupo, esta deve ser planejada como suporte e estímulo para o trabalho da escola e das instituições de saúde e como ponte para a integração deste público, quando suas dificuldades específicas forem superadas. O desafio dos planejadores é sempre o de integrar ações com caráter afirmativo no contexto institucional existente.

A oferta de serviços públicos para todos é obrigação do Estado, mas, como visto anteriormente, atuar para diminuir as desigualdades é uma tarefa para toda a sociedade, em que o Terceiro Setor possui papel fundamental e tem sido bastante efetivo. Ainda que muitas vezes o discurso dos empreendedores sociais que trabalham nas organizações não lucrativas apresente suas ações como reparadoras da ausência de Estado em certas áreas de atendimento, seu desempenho os leva com freqüência a preparar sua clientela para demandar seus direitos e conhecer as possibilidades de atendimento de suas demandas. Eles são, por sua própria prática, mediadores entre as agências que prestam serviços e o segmento que atendem e que iniciam na demanda por cidadania e participação.

Visto por este ângulo, o Terceiro Setor tem seu espaço e, o Estado, suas obrigações. A colaboração entre ambos estimula o protagonismo da sociedade civil em todos os níveis, assim como uma maior transparência para o conjunto das políticas sociais.

\section{CAMINHOS PARA CONTINUAR O DEBATE}

$\mathrm{Na}$ tentativa de resumir o debate sobre políticas sociais, visando sua continuidade, já têm-se alguns fatos sobre os quais refletir:

- a semelhança entre programas implementados em vários países, com governos de diferentes colorações políticas e ONGs de diversas posturas, faz pensar que estes planejamentos são quase sempre muito repetitivos e que falta uma análise da coerência entre os pressupostos atribuídos aos programas e as metodologias empregadas;

- certamente o desenho das políticas sociais está condicionado pelas opções políticas e por determinadas visões sobre desigualdade, mas as escolhas podem ser mais criteriosas se considerarmos os conhecimentos de que já dispomos. A facilidade com que se repetem experiências que não foram avaliadas ou que não tiveram bons resultados é impressionante, simplesmente porque os recursos precisam ser gastos ou as imagens que documentam as ações precisam ser divulgadas. Atualmente, já se dispõe de amplo conhecimento sobre monitoramento e avaliação de resultados, que deve ser usado pelos planejadores para aumentar a eficácia tanto na esfera pública como na privada;

- a participação da sociedade na promoção do desenvolvimento social já é uma realidade e conta com a mobilização tanto dos empresários e universitários quanto dos segmentos de baixa renda, cada qual com seu papel. A contribuição do Terceiro Setor na renovação de metodologias para programas sociais e a abertura de canais de participação local que dão voz aos que deman- 
dam oportunidades formam um novo contexto para a mudança social;

- o combate à pobreza tem sido uma obra de Penélope, em que o que se constrói durante um período se desmancha no momento seguinte. E, freqüentemente, se atribui aos pobres a resistência ao progresso. Atualmente sabese que a sustentabilidade das mudanças depende de desenho de programas que incluam a participação dos beneficiados e promovam o desenvolvimento do capital social que existe em todas as comunidades.

A firme disposição já existente entre os brasileiros para não mais se aceitar a extrema desigualdade social será promotora da continuidade do debate sobre a eficácia das políticas sociais.

\section{NOTA}

1. Para citar apenas alguns trabalhos dentro de um rico conjunto, ver: De Franco $(2001 ; 2002 ; 2003 ; 2004)$ e Putnam (1996).

\section{REFERÊNCIAS BIBLIOGRÁFICAS}

BARROS, R.; CARVALHO, M. Desafios para a política social brasileira. Rio de Janeiro: Ipea, 2003.

CARDOSO, R.C.L. Mudança sócio-cultural e participação política nos anos 80. In: SOLA, L.; PAULANI, L.M. (Orgs.). Lições da década de 80. São Paulo: Edusp; Genebra: UNRISD, 1995. p.193-200.

DE FRANCO, A. A revolução do local - globalização, glocalização, localização. Brasília: AED/São Paulo: Ed. Cultura, 2003/2004. . Três gerações de políticas sociais - Aminoá-c-i-d-o-s. Brasília: AED, n.5, p.85-106, 2003.

. Pobreza e desenvolvimento local. Brasília: AED, 2002. Capital social. Brasília: AED, 2001.

GRAHAM, C. From emergency employment to social investment. Washington, DC: The Brookings Institution, 1991.

JANVRY, A.; SADOULET, E. Analysis of the contigo strategy with enphasis on local and rural development. World Bank's Office in Mexico, 2003.

PUTNAM, R.D. Comunidade e democracia: a experiência da Itália moderna. Rio de Janeiro: Fundação Getúlio Vargas, 1996. 260 p.

VERGARA, P. Políticas hacia la extrema pobreza en Chile (19731988). FLACSO, 1990.

Ruth Corrêa Leite Cardoso: Presidente da organização não governamental Comunitas. Professora emérita de Antropologia e de Ciências Políticas na Universidade de São Paulo. Ex-presidente do Conselho da Comunidade Solidária. 